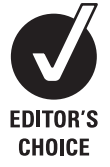

Department of Ophthalmology, University of Essen, Essen, Germany; ${ }^{2}$ Institute for Medical Informatics, Biometry and Epidemiology University of Essen, Essen, Germany:

${ }^{3}$ Department of Medicine, Division of Endocrinology, University of Düsseldorf, Düsseldorf, Germany;

${ }^{4}$ Department of Medicine, Division of Endocrinology, University of Essen, Essen, Germany; ${ }^{5}$ Institut für Experimentelle Endokrinologie und Endokrinologisches Forschungszentrum EnForCé, Charité, Universitätsmedizin Berlin, Campus Mitte, Berlin, Germany

Correspondence to: Dr A K Eckstein, Department of Ophthalmology, Essen University Hospital, Hufelandstr. 55 , 45122 Essen, Germany; anja.eckstein@uk-essen.de

Accepted 22 January 2009 Published Online First 16 February 2009

\title{
Euthyroid and primarily hypothyroid patients develop milder and significantly more asymmetrical Graves ophthalmopathy
}

\author{
A K Eckstein, ${ }^{1}$ C Lösch, ${ }^{2}$ D Glowacka, ${ }^{1}$ M Schott, ${ }^{3}$ K Mann, ${ }^{4}$ J Esser, ${ }^{1}$ \\ N G Morgenthaler ${ }^{5}$
}

\section{ABSTRACT}

Background and aims: Retrospective, observational study to compare clinical symptoms and TSH-receptor antibodies (TRAb) in Graves ophthalmopathy (GO) in euthyroid and primarily hypothyroid patients to those in hyperthyroid patients.

Methods: Clinical symptoms (NOSPECS (severity) and CAS (activity) score), prevalence and levels of thyroid specific antibodies and the course of the disease were evaluated in 143 primarily hyperthyroid, 28 primarily euthyroid and 11 primarily hypothyroid patients with GO Results: Patients with euthyroid/hypothyroid GO developed significantly less severe GO symptoms (NOSPECS score 4.4 vs $5.7 ; p=0.03$ ), less active GO (CAS score 3.9 vs $5.2 ; p=0.002$ ) and more asymmetrical disease (proptosis side difference: $1.9 \mathrm{~mm}$ vs $1.0 \mathrm{~mm}(\mathrm{p}=0.01)$; side difference of $\geqslant 3 \mathrm{~mm}$ : $23 \%$ vs $4.8 \%$ ) than hyperthyroid patients. TRAb levels 6 months after GO onset were significantly lower $(2.2 \mathrm{IU} / \mathrm{l}, \mathrm{p}=0.02)$ in euthyroid/hypothyroid than in hyperthyroid patients (8.6 IU/I), as was the prevalence of both TRAb and thyroid peroxidase antibodies (75\% vs $94.6 \%$, $p=0.0008$ ).

Conclusions: The knowledge about the phenotype of G0 in primarily euthyroid and hypothyroid patients is helpful for differential diagnosis and patient consultation. TRAb titres are very low in these patients, and the availability of a sensitive assay technique is therefore an important diagnostic tool in euthyroid and hypothyroid patients.

Graves ophthalmopathy (GO) usually occurs in a close temporal relationship with hyperthyroidism. It is rare in patients with normal thyroid function (euthyroid GO) and in patients with hypothyroid forms of thyroid autoimmune disease (hypothyroid GO). The prevalence of GO in primarily euthyroid and primarily hypothyroid patients ranges between 1.6 and $8.6 \% .^{1-4}$

Diagnosing GO is usually straightforward, but other diagnoses have to be considered in patients with normal thyroid function and only individual signs of GO such as isolated proptosis; these include cavernous carotid fistula, ${ }^{5}$ sphenoid meningioma and other tumours ${ }^{6}$ and lymphoma ${ }^{7}$ which may all also accompany GO itself. ${ }^{8}$

Determination of thyroid-specific antibodies contributes to the diagnosis of underlying thyroid disease. Khoo et al found positive results for thyroid-stimulating immunoglobulin (TSI; $93.8 \%$ ), a first-generation porcine TSH-binding inhibitory immunoglobulin (pTBII; 18.8\%) and a second-generation human TSH-binding inhibitory immunoglobulin (hTBII; 81.3\%) in 19 euthyroid patients among 1020 with GO. TRAb were detectable by at least one method in all patients. ${ }^{2}$ One-quarter of euthyroid patients develop thyroid dysfunction in the later course of the disease. ${ }^{2}$

The objectives of this study were to compare clinical symptoms in primarily euthyroid and primarily hypothyroid patients with those in patients with hyperthyroid $\mathrm{GO}$, and to investigate the levels of thyroid-specific antibodies in these patients.

\section{PATIENTS AND METHODS}

Ethics

The study was approved by the Medical Ethics Committee of the University Essen, Germany. Written consent to be included in the database and to draw blood was obtained from all participants.

\section{Study design}

This was a retrospective observational study on data selected from a GO database started in 2000 which includes findings in 893 consecutive patients treated at the University Hospital of Essen, Germany.

\section{Inclusion criteria}

Patients were included if they:

- presented within 6-12 months of onset of GO before anti-inflammatory treatment;

- were followed up for at least 12 months after onset of $\mathrm{GO} /$ until they reached inactivity;

- had TRAb and thyroid peroxidase (TPO) antibodies $(\mathrm{Ab})$ titres available 6 months after GO onset;

Consecutive primarily hyperthyroid patients out of the years 2003 and 2004 in the registry were selected as a control group.

\section{GROUPING OF THE PATIENTS}

\section{Hyperthyroid patients}

Patients who developed clinical or subclinical hyperthyroidism (elevated/normal fT4 and suppressed TSH) before or within 6 months after the onset of GO were assigned to the hyperthyroid group.

\section{Hypothyroid patients}

Patients who developed clinical or subclinical hypothyroidism (reduced/normal fT4 and elevated 
TSH) before or within 6 months after the onset of GO were considered as hypothyroid.

\section{Euthyroid patients}

Patients who had TSH and FT4 values within the reference range before and within 6 months after GO onset were assigned to the euthyroid group.

\section{Treatment}

Hyperthyroidism was treated with antithyroid drug (ATD) therapy for 1 year. Hyperthyroid patients who relapsed were given radioiodine therapy, underwent thyroidectomy or had a further cycle of ATD for 1 year, according to their preference. Hypothyroid patients were substituted with L-thyroxine to TSH levels between 0.5 and $1 \mathrm{mU} / 1$.

Concerning ophthalmopathy, all patients received standard anti-inflammatory treatment. During follow-up, all patients with clinical activity score (CAS) values $>2$ were offered treatment with steroids. For mild and moderate disease, they received an oral regime beginning with about $1.5 \mathrm{mg}$ fluorocortolone/mg body weight. Most of the the patients received $100 \mathrm{mg}$ as the starting dosage. Patients with a lower body weight started with 8 days of $90 \mathrm{mg}$ or 12 days of $80 \mathrm{mg}$ or 16 days of $70 \mathrm{mg}$ per day (according to the weight). Afterwards, the dosage was tapered by $10 \mathrm{mg}$ every 4 days. The treatment was finished with 4 days of $5 \mathrm{mg}$. Thus, the whole treatment duration was 44 days (cumulative dosage when starting with $100 \mathrm{mg} /$ day was $2.22 \mathrm{~g}$ ). For severe disease (increase/side difference of proptosis $\geqslant 3 \mathrm{~mm}$, reduced monocular excursions more than $15^{\circ}$, double vision in primary position, reduced vision) intravenous steroids (500 $\mathrm{mg} /$ day) were given three times within 5 days and followed by the same oral regime as above. Orbital irradiation was started if patients had impairment of motility and when the clinical activity score increased again after termination of steroids.

\section{Clinical assessment and follow-up}

Once the patients were included in the database, they were seen at regular intervals about once every 6-12 weeks usually until the end of the treatment ( 6 months of inactivity/no further ocular surgery). The control intervals were determined by the activity and severity of GO. At every visit, the following were assessed: visual acuity, lid width, downward movement of the lids $(\mathrm{mm})$, proptosis $(\mathrm{mm})$, inflammatory signs (redness and swelling of lids and conjunctiva) and eye motility (monocular excursions). If visual acuity was reduced, the cornea was stained with fluorescein, and if slit-lamp and fundus examination showed normal anatomy, optic-nerve function was assessed with visual evoked potentials.

The clinical activity score of GO (CAS) was estimated according to Mourits et al. ${ }^{9}$ The severity of the eye disease was estimated with a modified NOSPECS classification as described elsewhere. ${ }^{10}$

Patients were seen by an endocrinologist at regular basis if necessary all every 4 weeks, and thyroid treatment was given according to fT4 and TSH levels.

\section{Measurement of thyroid-specific antibodies}

TSH-receptor autoantibodies (TRAb) were measured at the first visit and at the regular control intervals during follow-up with a second-generation TSH-binding inhibitory (TBII) assay based on the human recombinant TSH-receptor (TRAK human LIA, B.R.A.H.M.S AG, Hennigsdorf, Berlin, Germany). ${ }^{11}$ This assay is calibrated in international units (IU), based on the WHO reference standard MRC 90/672. The 50\% inhibition of tracer binding corresponds to 7-8 IU/1. Values $\geqslant 1.5$ IU/1 (about 10\% tracer binding) were regarded as positive, values between 1 and $1.5 \mathrm{IU} / 1$ as borderline, and values $<1.0 \mathrm{IU} / 1$ as negative, as described in detail elsewhere. ${ }^{12}$ TPOAb were measured in a competitive luminescence immunoassay (BRAHMS anti-TPOn LIA BRAHMS AG). The threshold for positivity was $\geqslant 60 \mathrm{U} / \mathrm{ml}$.

\section{Outcome measures}

Clinical signs in all patients were assessed before antiinflammatory therapy or 6-12 months after the onset of GO in the absence of anti-inflammatory treatment.

The following parameters were compared among the groups:

- age;

- smoking behaviour;

- thyroid volume;

- TBII levels 6 months after first symptoms of GO;

- TPO Ab levels 6 months after first symptoms of GO;

- prevalence of positive TBII 6 months after first symptoms of GO;

- prevalence of negative TBII and TPO Ab 6 months after first symptoms of GO;

- CAS;

- NOSPECS;

- proptosis (mean/side difference);

- upgaze (monocular excursion);

- percentage of patients who had to receive steroid therapy;

- percentage of patients who had to receive orbital irradiation.

\section{Statistical analysis}

Group comparisons were tested for statistical difference with the Fisher exact test and the Mann-Whitney test (Graph pad prism 3.03 software). The Fisher exact test was used for crosstables of patient group versus binary variable (smoking status, dichotomised postive TBII level, dichotomised negative TBII and TPO Ab, dichotomised relative Hertel difference, steroid therapy and orbital irradiation). The number of patients in both groups was compared with an exact $\chi^{2}$ test. Because of the nonnormality of the remaining variables, the Mann-Whitney test was applied (age, thyroid volume, TBII levels, TPO Ab levels, CAS score, NOSPECS score, Hertel difference, degrees of upgaze, soft tissue inflammation). A $p$ value of $<5 \%$ was regarded as significant.

\section{RESULTS}

\section{Patients and epidemiological findings}

Evaluable records were available from 182 patients: 143 hyperthyroid (125 women and 18 men), 28 euthyroid, and 11 hypothyroid patients (31 women and 8 men). Concerning the whole database the prevalence of patients with euthyroidism or hypothyroidism at manifestation of GO was $4.2 \%$.

Patients were followed up for at least 12 months after GO onset, with a median of 36 months for the hyperthyroid patients and 27 months for the euthyroid and hypothyroid patients. Eighty-eight $(61.5 \%)$ of the hyperthyroid and 21 $(53.8 \%)$ of the euthyroid and hypothyroid patients were smokers. The median age of the hyperthyroid patients was 49 years (21-79) and 51 years (33-84) in the euthyroid and hypothyroid patients. None of these differences were 
Table 1 Patient and disease characteristics

\begin{tabular}{|c|c|c|c|}
\hline Characteristic & Hyperthyroid patients & $\begin{array}{l}\text { Euthyroid and } \\
\text { hypothyroid patients }\end{array}$ & p Values \\
\hline No of patients (male/female) & $143(18 / 125)$ & $39(9 / 31)$ & NS \\
\hline Age (years, median (range)) & 49 (21 to 79$)$ & 51 (33 to 84$)$ & NS \\
\hline Non-smoker/smoker & $55 / 88$ & $18 / 21$ & NS \\
\hline $\begin{array}{l}\text { Follow-up after first symptoms of G0 (months, } \\
\text { median (range)) }\end{array}$ & 36 (18 to 73$)$ & 27 (12 to 79$)$ & \\
\hline Thyroid volume (ml, mean (range)) & 23 (8 to 102) & 14 (2 to 36$)$ & $p<0.0001$ \\
\hline $\begin{array}{l}\text { TBII levels } 6 \text { months after first symptoms of } \\
\text { GO (IU/l, median (range)) }\end{array}$ & $8.6(<1.5$ to $>40.0)$ & $2.2(<1.5$ to $>40)$ & $p=0.02$ \\
\hline $\begin{array}{l}\text { Prevalence of positive TBII } 6 \text { months after first } \\
\text { symptoms of } \mathrm{GO} \text { (no (\%) of patients) }\end{array}$ & $134(94 \%)$ & $27(69 \%)$ & $\mathrm{p}<0.0001$ \\
\hline $\begin{array}{l}\text { Prevalence of negative TBII and TPO Ab } \\
6 \text { months after first symptoms of GO (no (\%) } \\
\text { of patients) }\end{array}$ & $8(5.6 \%)$ & $10(25 \%)$ & $p=0.0008$ \\
\hline $\begin{array}{l}\text { TPO Ab levels } 6 \text { months after first symptoms } \\
\text { of GO (U/ml, median (range)) }\end{array}$ & $262(<60$ to $>3000)$ & $100(<60$ to $>3000)$ & NS \\
\hline $\begin{array}{l}\text { Clinical activity score before anti-inflammatory } \\
\text { treatment }\end{array}$ & $5.2(2.34)$ & $3.9(2.1)$ & $p=0.002$ \\
\hline $\begin{array}{l}\text { NOSPECS score before anti-inflammatory } \\
\text { treatment }\end{array}$ & $5.7(3.1)$ & $4.4(2.4)$ & $p=0.03$ \\
\hline Hertel (mean (SD)) & $17.4(3.2)$ & $17.3(3.0)$ & NS \\
\hline Right-left difference (mean (SD)) & $1.0(1.0)$ & $1.9(1.8)$ & $p=0.01$ \\
\hline Percentage difference $\geqslant 3 \mathrm{~mm}$ & $4.8 \%$ & $23 \%$ & $p=0.004$ \\
\hline $\begin{array}{l}\text { Upgaze (monocular excursion) (median } \\
\text { (range)) }\end{array}$ & $30(5$ to 40$)$ & 35 (5 to 40$)$ & $p=0.04$ \\
\hline Steroid therapy (no (\%) patients) & $124(87 \%)$ & $31(79 \%)$ & NS \\
\hline Orbital irradiation (no (\%) patients & $98(68 \%)$ & $15(38 \%)$ & $p=0.03$ \\
\hline
\end{tabular}

GO, Graves ophthalmopathy; SD, standard deviation; TBII, TSH-binding inhibitory immunoglobulin; TPO Ab, thyroid peroxidase antibodies.

statistically significant. Patient and disease characteristics are given in table 1.

\section{Ophthalmological findings}

Representative patient examples are given in fig 1. All three patients show the typical asymmetrical unilateral manifestation of GO in euthyroid and primarily hypothyroid patients. The diagnosis in the first patient was straightforward (fig 1A-C) because of the typical inferior rectus and levator palpeprae involvement and the soft-tissue inflammation. Although thyroid-specific antibody levels in the borderline range had been measured once, this patient had not developed thyroid abnormality after 19 months of follow-up. The patient in fig 1D-F was referred for biopsy with a suspected diagnosis of lymphoma with normal thyroid function. Closer thyroid workup revealed positive TPOAb $(168 \mathrm{U} / \mathrm{ml})$ and TRAb in the borderline range. The patient developed hypothyroidism during follow-up, and lid lengthening was done after 18 months of follow-up. The euthyroid patient in fig $1 \mathrm{G}-\mathrm{K}$ developed unilateral proptosis which progressed over 1 year, despite steroid treatment. TRAb were $2.4 \mathrm{IU} / 1$ at diagnosis and undetectable after 1 year. Repeated CT scans revealed only an increase in adipose tissue behind the eye. The patient was transnasaly decompressed after 3 years' follow-up.

Clinical signs in all patients were assessed before antiinflammatory therapy or 6-12 months after the onset of GO in the absence of anti-inflammatory treatment. At the time of assessment according to the fT4 values, most of the patients were euthyroid (94\% of the primarily hyperthyroid patients, $97 \%$ of the primarily hypothyroid/primarily euthyroid patients, NS).

Euthyroid and hypothyroid patients were similar and developed significantly less severe GO symptoms (NOSPECS score 5.7 vs 4.4; $\mathrm{p}=0.03$ ) and a less active GO (CAS score 5.2 vs 3.9; $p=0.002)$ than hyperthyroid patients. The frequencies of the typical manifestations of $\mathrm{GO}$ in both groups are displayed in fig 2. Euthyroid and primarily hypothyroid patients had significantly less soft-tissue inflammation (82\% vs $96 \%$, $\mathrm{p}=0.007$ ) and, if soft-tissue inflammation was already present, did not worsen so severely (fig 2C). None of the euthyroid or hypothyroid patients developed optic neuropathy, while 10 $(7 \%)$ primarily hyperthyroid patients did. Median monocular excursions were significantly $(p=0.04)$ less reduced in the euthyroid and hypothyroid GO patients (median $35^{\circ}$ ) than in the hyperthyroid patients (median $30^{\circ}$ ). The mean Hertel values were very similar in both groups, but there was a significantly higher side difference between both eyes $(1.0 \mathrm{~mm}$ (hyperthyroid patients) vs $1.9 \mathrm{~mm}$ (euthyroid and hypothyroid patients); $\mathrm{p}=0.01$ ). Significantly more euthyroid and hypothyroid patients $(23 \%)$ developed very asymmetrical GO with a proptosis difference of $\geqslant 3 \mathrm{~mm}(p=0.004)$ (fig $2 \mathrm{~B}$ ).

Both patient groups received equal amounts of steroids, but irradiation was necessary in only $38 \%$ of the euthyroid and hypothyroid patients in comparison with $68 \%$ of the hyperthyroid patients $(p=0.03)$.

\section{Endocrinological findings}

The mean thyroid volume was $13 \mathrm{ml}$ (SD 7.6; range 2-36) in euthyroid and hypothyroid patients and was significantly smaller than in hyperthyroid patients $30 \mathrm{ml}$ (SD 22; range 8-102).

TRAb levels 6 months after GO onset were significantly higher in hyperthyroid patients (median: $8.6 \mathrm{IU} / \mathrm{l}$ ) than in euthyroid and hypothyroid patients (median: $2.2 \mathrm{IU} / 1 ; \mathrm{p}=0.02$ ) (fig 3). Median TPOAb levels 6 months after GO onset were not significantly different: $262 \mathrm{IU} / 1$ in hyperthyroid patients and $100 \mathrm{IU} / 1$ in euthyroid and hypothyroid patients.

Six months after the first symptoms of GO, only 27 (69\%) of the euthyroid and hypothyroid patients had positive findings 
Figure 1 Representative examples of euthyroid and hypothyroid patients. (A) Enface photograph of a 46-year-old patient with severe left unilateral GO with soft tissue inflammation, proptosis and marked impairment of motility. (B) Coronary and transverse (C) MRI scans showing thickening and inflammation, especially of the inferior rectus and levator palpeprae muscle. (D) Enface photograph of a 48-year-old patient with mild right unilateral GO with upper lid swelling and retraction, and mild dacryoadenitis, who was referred for biopsy with suspected diagnosis of lymphoma. $(E, F)$ representative MRI scans of patient $D$ showing mild dacryoadenitis and levator palpeprae muscle thickening and inflammation. (G) Enface photograph of a 34-year-old patient with right unilateral $\mathrm{GO}$ with proptosis without any other sign of G0, with suspected diagnosis of retrobulbar tumour. (H) MRI showing only and increase in retrobulbar adipose tissue. (I, K) Photographs from the left and right hand side showing the degree of proptosis.
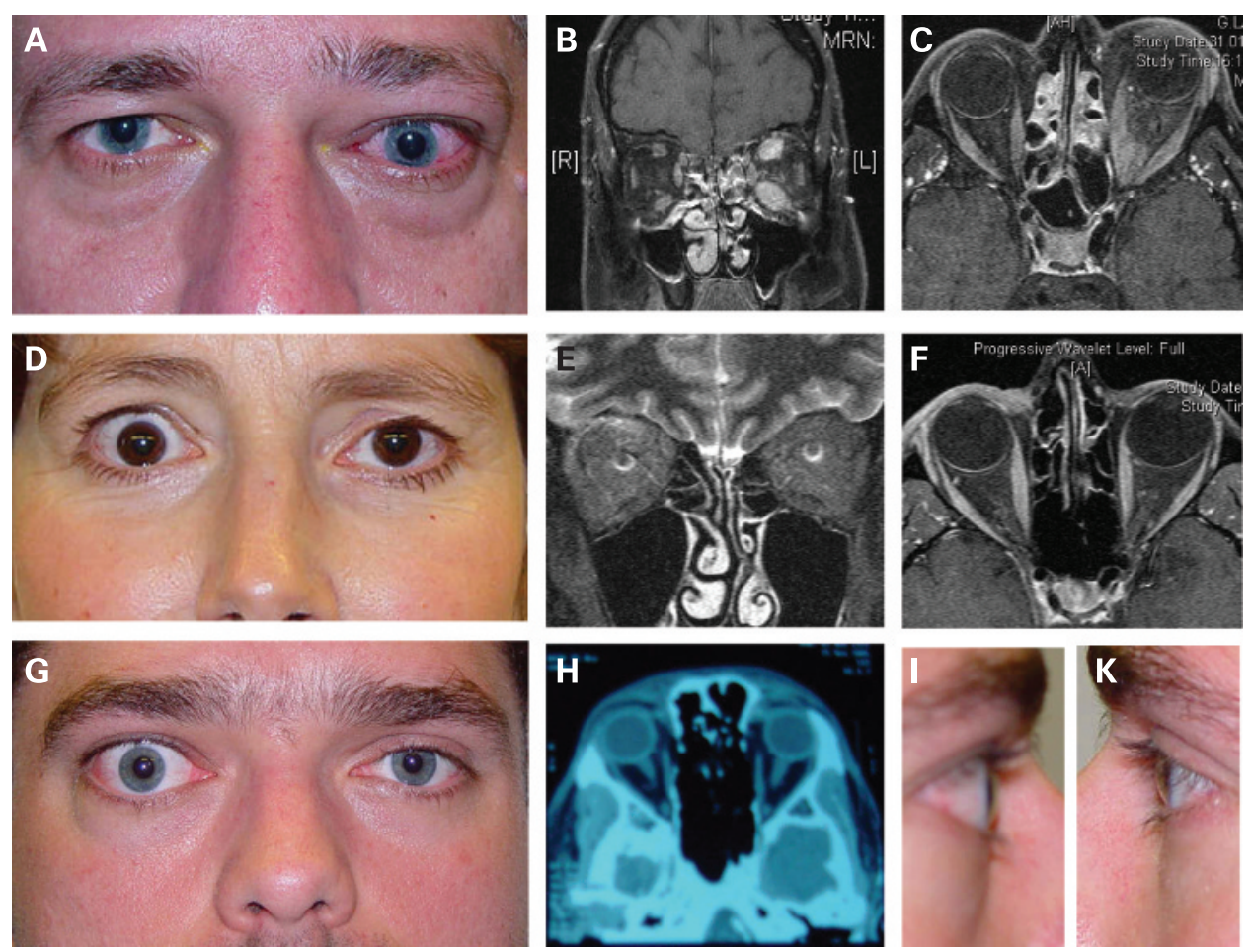

for TRAb, while findings were positive in 134 (94\%) hyperthyroid patients. This difference was statistically significant $(\mathrm{p}<0.0001)$. Regarding TRAb and TPOAb together, still 10 out of $39(25 \%)$ euthyroid and hypothyroid patients were negative for both antibodies in comparision with only eight out of $143(5.6 \%)$ hyperthyroid patients $(p=0.0008)$.

During the follow-up, six of the euthyroid patients $(20.7 \%)$ developed hypothyroidism which was substituted with Lthyroxine. Two patients (6.8\%) became hyperthyroid and received ATD. Among the hyperthyroid patients, following ATD treatment, 29 patients $(20.3 \%)$ went into thyroid disease remission, while 114 patients (79.7\%) needed definitive thyroid therapy (radioiodine therapy or thyroidectomy).

\section{DISCUSSION}

The clinical signs and symptoms of GO in primarily euthyroid and hypothyroid patients differ from those in primarily hyperthyroid patients: primarily euthyroid and hypothyroid patients show less soft-tissue involvement and more asymmetrical disease, and the clinical manifestations are less marked. Unilateral GO has often been reported in case reports of primarily euthyroid patients. ${ }^{13-15}$

The diagnosis of GO is considerably impeded by monosymptomatic and asymmetrical manifestations, especially in primarily euthyroid patients, and diagnostic imaging is indicated in all such patients. ${ }^{5-7} 1516$

There is a close temporal relationship between the onset of hyperthyroidism and the onset of $\mathrm{GO}$, but $4-18 \%{ }^{17}{ }^{18}$ of the patients with Graves disease develop thyroid dysfunction after the onset of GO, most within 1 year of the onset of eye symptoms. Regular thyroid function tests are therefore indicated in primarily euthyroid patients. About one-quarter of primarily euthyroid patients will develop thyroid dysfunction within 4 years. Predictors of this were shown to be suppressed
Figure 2 (A) Clinical symptoms of patients with Graves ophthalmopathy (GO) and primary hyperthyroidism (black) in comparison with patients with $\mathrm{GO}$ and euthyroid or primarily hypothyroid disease (grey). (B) Percentage of patients with a proptosis difference of $\geqslant 3 \mathrm{~mm}$. (C) Intensity of soft-tissue inflammation.

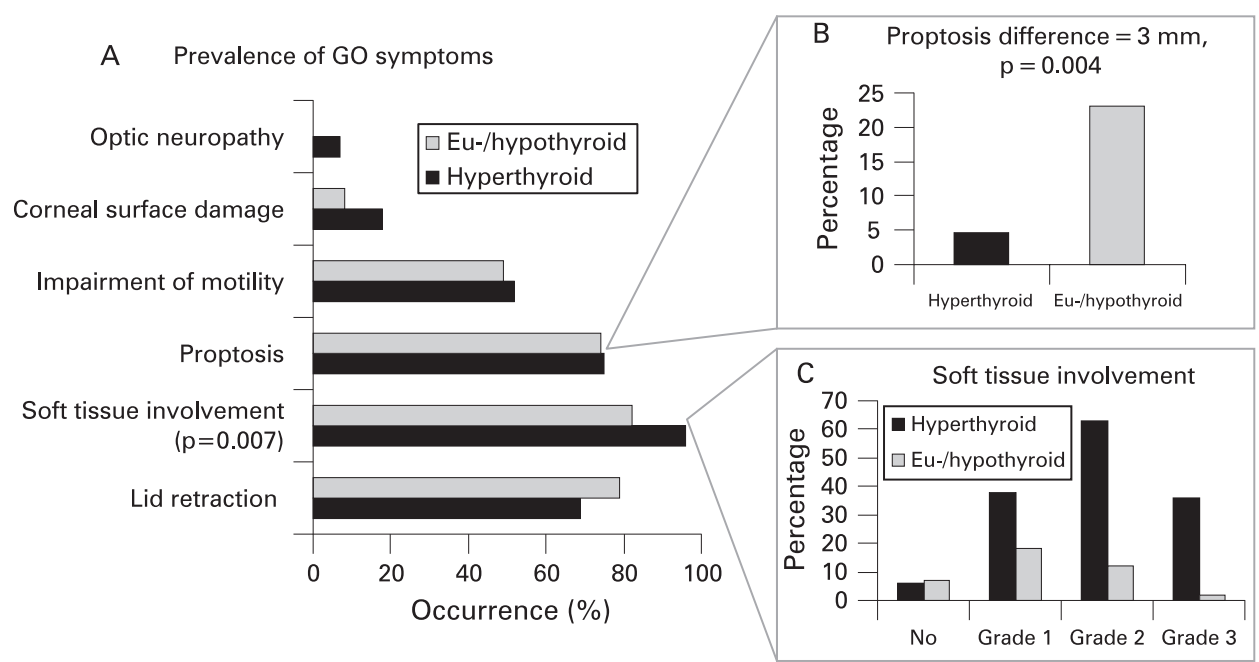




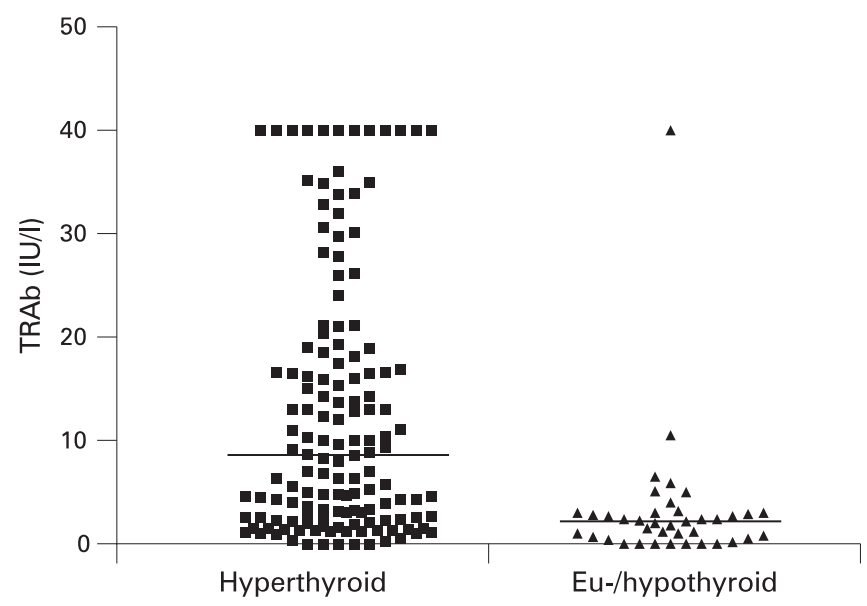

Figure 3 TSH-receptor antibodies (TRAb) values in primarily hyperthyroid and primarily euthyroid and/hypothyroid patients 6 months after Graves ophthalmopathy onset.

TSH and positive TRAb. ${ }^{2}$ Other minor abnormalities (uneven uptake and the presence of hot or warm lesions), which indicate thyroid involvement in primarily euthyroid patients with GO, are seen in the scintigram. ${ }^{19}$

Thyroid antibodies are specific indicators for thyroid autoimmunity. Positive TRAb levels confirmed the diagnosis of GO in $69 \%$ of the euthyroid and hypothyroid patients. Taking $T R A b$ and TPOAb together, the diagnoses of thyroid associated ophthalmopathy could be confirmed even in $75 \%$ of the patients. In former studies the long-acting thyroid stimulator protector (LATS) has also been used as an indicator for thyroid autoimmunity in euthyroid patients with normal-sized glands. ${ }^{20}$ A sensitive test for TRAb in euthyroid patients is necessary because titres are much lower than in primarily hyperthyroid patients. The rate of detection of TBII in euthyroid patients in the second-generation assay has been shown to be significantly higher than that with the first-generation assay ( $81 \%$ vs $18 \%){ }^{2}$

Thyroid-stimulating immunoglobulin (TSI) measurement has been reported to be a useful and possibly more sensitive marker of euthyroid GO than TBII measurement in Asians. ${ }^{21}{ }^{22}$ This is also the case for primarily hyperthyroid patients. ${ }^{23}$ Because TSI are less prevalent in white patients, TSI measurement may not be an appropriate predictor of $\mathrm{GO}$ in these patients. ${ }^{24}{ }^{25}$ It must, however, be borne in mind that these results came from different laboratories and that the bioassays used in Asia may have been more sensitive.

\section{Competing interests: None.}

Ethics approval: Ethics approval was provided by the Medical Ethics Committee of the University Essen, Germany.

Patient consent: Obtained.

\section{REFERENCES}

1. Bartley GB, Fatourechi V, Kadrmas EF, et al. Clinical features of Graves' ophthalmopathy in an incidence cohort. Am J Ophthalmol 1996;121:284-90.

2. Khoo DH, Eng PH, Ho SC, et al. Graves' ophthalmopathy in the absence of elevated free thyroxine and triiodothyronine levels: prevalence, natural history, and thyrotropin receptor antibody levels. Thyroid 2000;10:1093-100.

3. Marcocci C, Bartalena L, Bogazzi F, et al. Studies on the occurrence of ophthalmopathy in Graves' disease. Acta Endocrinol (Copenh) 1989;120:473-8.

4. Paunkovic J, Paunkovic N. Does autoantibody-negative Graves' disease exist? A second evaluation of the clinical diagnosis. Horm Metab Res 2006;38:53-6.

5. Lore F, Polito E, Cerase A, et al. Carotid cavernous fistula in a patient with Graves' ophthalmopathy. J Clin Endocrinol Metab 2003;88:3487-90.

6. Asproudis IC, Petsanas AP, Nikas AN, et al. A sphenoid en plaque meningioma aggravates exophthalmos in a patient with thyroid ophthalmopathy. Eur J Ophthalmol 2006;16:461-4.

7. Boyce PJ. Orbital lymphoma masquerading as thyroid ophthalmopathy. J Am Optom Assoc 1998;69:666-73.

8. Stark JJ, Newsom RW, Roman J, et al. Orbital MALT lymphoma in a patient with Graves' ophthalmopathy: a unique observation. Cancer Invest 2005;23:593-5.

9. Mourits MP, Prummel MF, Wiersinga WM, et al. Clinical activity score as a guide in the management of patients with Graves' ophthalmopathy. Clin Endocrinol (Oxf) 1997;47:9-14.

10. Eckstein AK, Plicht M, Lax H, et al. Thyrotropin receptor autoantibodies are independent risk factors for Graves' ophthalmopathy and help to predict severity and outcome of the disease. J Clin Endocrinol Metab 2006;91:3464-70.

11. Costagliola S, Morgenthaler NG, Hoermann R, et al. Second generation assay for thyrotropin receptor antibodies has superior diagnostic sensitivity for Graves' disease. J Clin Endocrinol Metab 1999;84:90-7.

12. Schott M, Feldkamp J, Bathan C, et al. Detecting TSH-receptor antibodies with the recombinant TBII assay: technical and clinical evaluation. Horm Metab Res 2000; 32:429-35.

13. Lawton NF. Exclusion of dysthyroid eye disease as a cause of unilateral proptosis Trans Ophthalmol Soc UK 1979:99:226-8.

14. Lumera G, Prummel MF, Baldeschi L, et al. Unilateral Graves Orbitopathy: a case control and retrospective follow up study. Turkish Journal of endocrinology and metabolism 2004;8(1 Suppl):63S.

15. Perrild $\mathbf{H}$, Feldt-Rasmussen U, Bech K, et al. The differential diagnostic problems in unilateral euthyroid Graves' ophthalmopathy. Acta Endocrinol (Copenh) 1984;106:471-6.

16. Merlis AL, Schaiberger CL, Adler R. External carotid-cavernous sinus fistula simulating unilateral Graves' ophthalmopathy. J Comput Assist Tomogr 1982;6:1006-9.

17. Bartley GB, Fatourechi V, Kadrmas EF, et al. Chronology of Graves' ophthalmopathy in an incidence cohort. Am J Ophthalmol 1996;121:426-34.

18. Wiersinga WM, Smit T, van der Gaag R, et al. Temporal relationship between onset of Graves' ophthalmopathy and onset of thyroidal Graves' disease. J Endocrinol Invest 1988;11:615-19.

19. Kasagi K, Hidaka A, Misaki T, et al. Scintigraphic findings of the thyroid in euthyroid ophthalmic Graves' disease. J Nucl Med 1994;35:811-17.

20. Solomon DH, Chopra IJ, Chopra U, et al. Identification of subgroups of euthyroid graves's ophthalmopathy. New Engl J Med 1977;296:181-6.

21. Watanabe M, Iwatani $Y$, Kashiwai T, et al. Euthyroid Graves' disease showing no thyroid abnormalities except positive thyroid-stimulating antibody (TSAb): two case reports. J Intern Med 1995; 238:379-84.

22. Kazuo K, Fujikado T, Ohmi G, et al. Value of thyroid stimulating antibody in the diagnosis of thyroid associated ophthalmopathy of euthyroid patients. Br J Ophthalmol 1997;81:1080-3.

23. Khoo DH, Ho SC, Seah LL, et al. The combination of absent thyroid peroxidase antibodies and high thyroid-stimulating immunoglobulin levels in Graves' disease identifies a group at markedly increased risk of ophthalmopathy. Thyroid 1999;9:1175-80.

24. Gerding MN, van der Meer JW, Broenink M, et al. Association of thyrotrophin receptor antibodies with the clinical features of Graves' ophthalmopathy. Clin Endocrinol (Oxf) 2000;52:267-71.

25. Eckstein AK, Plicht M, Lax H, et al. Clinical results of anti-inflammatory therapy in Graves' ophthalmopathy and association with thyroidal autoantibodies. Clin Endocrinol (Oxf) 2004;61:612-18. 